\title{
Beyond the Principle of Sufficient Reason? Schopenhauer's Aesthetic Phenomenology Bart Vandenabeele
}

Schopenhauer's claims about the principle of sufficient reason face several significant problems, not in the least because he is adamant that his theory of knowledge is compatible with a metaphysical view that distinguishes sharply between the phenomenal world (the world as representation) and the world as it is in itself (the world as will). His intriguing analysis of the peculiar type of perception he qualifies as aesthetic further complicates matters, as it is also intricately linked up with his dyadic conception of will and representation. Since Schopenhauer insists that perceiving an object aesthetically requires an exceptional attitude which enables us to pierce the veil of Maya and capture a glimpse of how the will manifests itself most adequately in (or as) Ideas, the question arises not only what are the specific features of such a kind of knowledge beyond the principle of sufficient reason, but also whether qualifying aesthetic cognition in this way may lead to a coherent phenomenology of aesthetic experience which safeguards the life-affirming nature of the aesthetic. Those two questions, which will guide us in what follows, are of the utmost importance in the broader context not only of Schopenhauer's epistemology and philosophy of mind but also of his philosophy as a whole, for (or so I shall argue) answering them in a satisfactory way will enable us to give the lie to those who, like Nietzsche, unjustly repudiate his view of aesthetic experience as misguided and ultimately hostile to life.

First, then, I will briefly discuss the tenets of Schopenhauer's theory of sensory perception. I then contrast this with his account of aesthetic perception and cognition (ästhetische Anschauung und Erkenntnis), which arguably transcends the principle of sufficient reason. Further, I aim to show that the consensus view of Schopenhauer's theory of the aesthetic 
attitude, which reduces it to spiritual detachment and disembodied cognition is wholly inadequate. Even focussing on Schopenhauer's account of the beautiful (and disregarding his theory of the sublime) should suffice to show that, in Schopenhauer's view, aesthetic perception can really be active, imaginative and genuinely life-affirming. ${ }^{1}$

I shall thus argue that Schopenhauer offers a rich phenomenological account of aesthetic experience, which shows that appreciating beautiful objects requires suspending our individual needs, desires and appetites. This experience of depersonalisation, by which a willing individual feels himself to be transformed into a 'pure subject of knowledge', does not imply a glorification of dispassionate spectatorship, as Nietzsche and many other commentators have maintained, but rightly emphasises that aesthetic contemplation is imaginative as well as enthusiastic, and - as we shall see - requires a genuine interest in the intrinsic value of an object.

\section{Sensory Perception and Aesthetic Experience}

One of Schopenhauer's explicit goals is to naturalise Kant's theory of knowledge and to defend the value of embodied perception against idealising tendencies in Kant's epistemology and that of his followers. Schopenhauer criticises Kant's Critique of Pure Reason for being too much concerned with pure intuition and abstract judgement and reasoning, and he therefore develops a detailed account of the role of the body and, more specifically, of the senses in intuitive perception and knowledge of the world (see FR, $§ 17-$ 25). Anticipating Nietzsche's views on embodied cognition but also phenomenologists such as Husserl and (especially) Merleau-Ponty, Schopenhauer contends that gaining adequate insight into knowledge and perception cannot proceed wholly along the lines of Kant and his

\footnotetext{
${ }^{1}$ For a thorough critical examination of Schopenhauer's account of the sublime, see my book The Sublime in Schopenhauer's Philosophy.
} 
idealistic followers Fichte, Schelling and Hegel. For whilst Fichte held that the non-ego could be derived from the ego, "like a web from a spider" (WWR 1, 40), which turns the object into the effect of the subject, Schopenhauer insists not merely on the embodied nature of the subject, but also argues that the subject and the object of perception are correlative. For the principle of sufficient reason presupposes the object, but is not valid before and outside it (see WWR $1, \S 7$ ). The subject of knowledge and the object are not related to each other as cause and effect, but presuppose one another a priori. They are ultimately two sides of a single indivisible act of consciousness, of what Husserl calls an 'intentional act'.

Since the law of causality applies only within the world of representation, it cannot be applied properly to explain the correlation between subject and object. Representation is fundamentally 'bipolar'. It is of the utmost importance to note that Schopenhauer argues that this subject-object correlation is presupposed in all forms of cognition, hence including aesthetic cognition. Schopenhauer is faithful to Kant in defending the 'transcendental ideality' of the whole world of objects (WWR $1, \S 7$ and passim; see also FR, $\S 18-19$ and passim), but he supplements this transcendental perspective with a naturalised account of how complete causal knowledge of objects of perception is possible (see FR, § 21). For Schopenhauer's insight that subject and object are correlative does not imply that the objects of perception do not causally interact with us. Schopenhauer is not a sceptic and he thus urges that causal action exhausts the objects' (empirical) being. The perceived world in space and time, which includes perception of ourselves as embodied individuals, is perfectly real.

Yet how perceptual objects can be both a construct of the understanding (for they are transcendentally ideal) and yield the causal ground for perception remains unclear. As I argued elsewhere in more detail, this creates a number of complex paradoxes, which could 
only be disentangled if either Schopenhauer abandoned the naturalisation of his theory of knowledge, or he accepted that the physical objects that provide the 'raw material' for objective intuitions are radically different from the intuitions constructed on the basis of sensory perception, or he were prepared to reject the a priori nature of cognition and subject-object correlation altogether. ${ }^{2}$

These problems and paradoxes should not, however, blind us to the subtlety of Schopenhauer's account of cognition, which offers a rich panorama of the mechanisms of sensory perception. Developing and criticising some of Kant's anthropological views, and anticipating 20-th century phenomenological theories, he explores the richness and value of the senses. This is not the place to offer a detailed survey of Schopenhauer's hierarchy of the senses. ${ }^{3}$ One of its more intriguing aspects should be taken into account, however, for it is directly related to the topic of this essay, since it connects, in a somewhat unexpected way, ordinary and aesthetic perception. In Schopenhauer's discussion of sensory perception the sense of sight possesses a privileged status. This is not surprising, for this privilege has dominated Western philosophy at least since Plato. Yet according to Schopenhauer, the sense of sight is to be distinguished qualitatively from the other senses for several rather surprising reasons.

First of all, the sense of sight is distinguished from the other senses, because it is the aesthetic sense par excellence. The reason for this is directly relevant to the issue of how and why aesthetic cognition could be cognition 'beyond' the principle of sufficient reason. For, unlike the other senses, the sense of sight can be affected without being immediately experienced as pleasurable or unpleasant. From this point of view it is more 'objective' than the other senses. Whereas the clearly 'subjective' senses, smell and taste, are emitted by

\footnotetext{
${ }^{2}$ See my The Sublime in Schopenhauer's Philosophy, Ch. 2.

${ }^{3}$ See my The Sublime in Schopenhauer's Philosophy, p. 41-46.
} 
things and can linger in the places from which their causes have departed, the sense of sight (and, up to a certain point, also the sense of hearing) is related in a different way to its causal object. The visual appearance of my kitchen does not linger in a place after the kitchen has left it, and the kitchen is not represented in its smell in the way that it is in its visual image. In Schopenhauer's idiom, smells exist for our will. And if they are aesthetically interesting at all, it is through association and not through what I experience in the object, that is, it is through how it immediately affects me, through what it brings to mind, rather than through the meaning that we capture in the object.

Schopenhauer thus characterises seeing as 'objective', but he uses the latter term in at least two distinct senses: not immediately connected to an affective stirring of our will, on the one hand, and being capable of realising an objective intuition (Anschauung), on the other hand (see also FR, § 21). This rather confusing usage may not be as innocent as we might suppose, for it ought to direct our attention to the important problem of the intelligibility of what Schopenhauer calls 'will-less perception', i.e. a way of perceiving objects that is not dominated by the interests of our will. A kind of perception that is 'pure' and somehow 'uprooted', i.e. disconnected from the roots of the principle of sufficient reason that determine ordinary sensory perception.

Common perception is not disinterested, Schopenhauer argues, but directs its "attention to things that stand in some sort of relation to his will", and "only ever affords cognition of relations" (WWR 1, 220-221). But does that imply that all will-less perception is necessarily disconnected from cognition which is determined by the principle of sufficient reason? To be able to answer this question we should focus first on what Schopenhauer considers to be the proper target of aesthetic cognition, namely the Platonic Idea. Only after that will we be able to grasp the richness of Schopenhauer's analysis of the subjective component of aesthetic 
contemplation and obtain a more adequate understanding of why objective cognition that is not subservient to the principle of sufficient reason does not necessarily imply dispassionate, disembodied contemplation.

\section{The Objects of Aesthetic Perception: Platonic Ideas}

In emphasising that universals and not particulars are the proper object of aesthetic perception, Schopenhauer engages in a long tradition of idealist philosophers, including Plotinus, Schelling and Hegel. This metaphysical tradition has always stressed the thought that aesthetic perception distinguishes itself from ordinary perception by focussing on an Idea that is embodied in a particular work of art. Much later, in the same vein, Arthur Danto will defend the view that works of art are to be distinguished from ordinary objects by being characterised by aboutness, i.e. by the fact that the former are external shapes that embody ideas - that are the content of the work of art, that which the work is about.

Despite prima facie similarities with this idealist tradition, which culminates in Hegel's and Danto's focus on ideas as the content of works of art, Schopenhauer's aesthetic theory is manifestly different from it in a number of significant ways. The hugely important differences between Schopenhauer's theory and his idealist colleagues are deeply connected with the problem of the principle of sufficient reason. Discussing all the discrepancies between Schopenhauer's views and the Hegelian strand of thought obviously falls beyond the scope of this essay. Here I shall focus on Schopenhauer's arguments with regard to aesthetic cognition and its objective correlates.

According to Schopenhauer, the target of aesthetic appreciation is neither the relation of the object to our personal interests, nor the relation of the object with other objects. Ordinary cognition is not merely guided by but determined by personal needs, appetites, and 
emotions. Aesthetic consciousness, by contrast, is a superior form of cognition which is " $a$ way of regarding things independently from the principle of sufficient reason", and is based upon "the capacity ... to lose oneself in intuition and to withdraw cognition that originally only existed in its service to the will from this service", and yields insight into what the object truly is (WWR 1, 218-219). Aesthetic, will-less perception yields 'objective' insight from the standpoint of eternity ${ }^{4}$, i.e. into the timeless kernel of things, that is, the universal essences of the perceived objects, beyond mere appearance. This neo-Platonic approach identifies the objects of aesthetic consciousness with the timeless forms behind the mere appearances of common ordinary cognition, that is to say, Platonic Ideas.

Now, whilst common perception is always necessarily related to the individual's will and always demands only knowledge of the relations, i.e. knowledge determined by the principle of sufficient reason for which the abstract concept of the thing is sufficient, aesthetic consciousness offers a type of insight which surpasses merely conceptual knowledge and strives to grasp the Idea in and through the particular aesthetic object. The core of the objects are thus known by a peculiar type of imaginative perception. (I will come back to this in the final part of this essay.)

Yet Schopenhauer's Platonic jargon should not deceive us. For Schopenhauer's aesthetic Ideas differ in a number of important ways from their counterparts in Platonic philosophy. Whereas for Plato the Ideas are the ontological essences of the whole world, i.e. the eternal universals that form the ultimate components of reality as a whole, for Schopenhauer they are the correlates of aesthetic imaginative perception and adequately manifest the abysmal core of the world, the one ultimate kernel of things, namely will. With the exception of

\footnotetext{
${ }^{4}$ More details on the objective character of aesthetic cognition can be found in my essay on 'Schopenhauer and the Objectivity of Art'.
} 
music $^{5}$, which is a direct copy of the will, Schopenhauer insists that all other art forms and aesthetic experiences cannot gain direct insight into the metaphysical core of the world, but merely indirectly, that is through its endless plurality of timeless Ideas, which in turn are embodied in concrete particulars, be it natural beauties or works of art.

Furthermore, and this is hugely important in the context of the problem of the relation between aesthetic cognition and the scope of the principle of sufficient reason, Schopenhauer refers to the categories of the understanding (or intellect) to construct a complex argument for the peculiar epistemological and metaphysical status of the Ideas in aesthetic perception.

We can summarise Schopenhauer's reasoning as follows:

i. the categories of space, time and the categories of the understanding (the principle of sufficient reason) construct the world as representation;

ii. the world as representation therefore consists of multiple representations or different objects;

iii. the principle of sufficient reason is limited to the world as representation;

iv. the principle of sufficient reason does not apply to the thing-in-itself (the noumenon);

v. the thing-in-itself beyond all phenomena cannot be characterised by multiplicity;

vi. the Ideas are characterised by multiplicity;

vii. the Ideas cannot be the noumenal thing-in-itself.

Needless to point out that there are several problems with Schopenhauer's reasoning, especially concerning the awkward place occupied by the Platonic Ideas in the metaphysical realm. For the Platonic Ideas are not merely the most adequate objectifications of will, they

\footnotetext{
${ }^{5}$ See Lydia Goehr, 'Schopenhauer and the Musicians'.
} 
clearly belong to the domain of representation, for (unlike the thing-in-itself) they are characterised by plurality, whereas they cannot be grasped by the kind of cognition that is determined by the ordinarily applying categories of understanding. The Ideas seem to be both within and beyond the world as representation, they seem to belong to the world as will, for they offer the most adequate access to the thing-in-itself, but they also seem to belong to the world as representation, for they are not only characterised by multiplicity (as all particular objects are) but are also grasped by a superior kind of cognition, which pierces through the veil of Maya. However, aesthetic perception offers merely another veiled access, which deceives us into believing that the plurality of Ideas are the ultimate components of reality, since for Schopenhauer the Platonic Ideas are neither concepts (as seems the case in Platonic philosophy), nor merely the products of the power of imagination (as the aesthetic ideas are in Kant's theory of art), nor the ideal revelation of the Absolute (as in Schelling and Hegel).

Although the ambivalent and complicated status of Schopenhauer's 'semi-Platonic' idealism cannot be ignored, understanding the specific characteristics of aesthetic perception and cognition does not presuppose the belief that the Platonic Ideas are the adequate objectifications of the will. For despite its differences with ordinary cognition, aesthetic cognition necessarily remains tied to empirical perception. A proper characterisation of the value of Schopenhauer's aesthetic theory should take into account his (anti-Hegelian) rehabilitation of sensory perception and its relevance to aesthetic contemplation and artistic creativity. Schopenhauer's aesthetic theory does not merely attempt to answer Plato's repudiation of the arts by offering a Platonic reply to it, as Christopher Janaway suggests ${ }^{6}$, he also aims to develop an explanation of aesthetic appraisal which avoids the Platonic-

\footnotetext{
${ }^{6}$ See Christopher Janaway, 'Knowledge and Tranquillity'.
} 
Hegelian trap of demoting the senses in favour of spiritual contemplation. Although Schopenhauer (rightly) departs from Kant's transcendental approach, which is entirely preoccupied with a critique of aesthetic judgement, and defends an aesthetic attitude theory which centres on aesthetic contemplation, he justly emphasises that aesthetic cognition involves sensory perception, and is thus necessarily a form of embodied cognition, and that its significance is intimately connected with the rich variety of the senses.

For Schopenhauer's admiration for Plato's idealism should not be confused with a defence of some version of intellectualist aesthetics. On the contrary, Schopenhauer repeatedly warns against identifying Ideas with concepts, and insists that the latter are useless and even deleterious to aesthetic experience and the creation of art. Concepts are useful in ordinary life and necessary and productive in science, Schopenhauer holds, but they "will always be barren for art" (WWR 1, 277). Yet, artistic Ideas "develop representations that are novel with respect to concepts sharing the same name: the Idea is like a living and developing organism endowed with generative powers, an organism that can produce things that were not already packaged up inside it" (ibid.).

Contrary to Hegel and other idealists, Schopenhauer also holds that concepts are merely mental constructs that aid in grasping reality in general terms, whereas Ideas cannot be discovered by conceptual thinking, but solely by intuition or perception (Anschauung) and imagination (Phantasie). Aesthetic contemplation transports me out of myself and suspends my merely personal concerns and ambitions, but I do not therefore become a 'pure intellect' or 'pure spirit' (neither in a Platonic nor in a Hegelian sense). Moreover, Schopenhauer vehemently opposes merely conceptual and allegorical works of art, "in which we see the distinct, limited, cold dispassionate concept glimmer and finally appear": such works deserve nothing but our "disgust and indignation, for we see ourselves deceived and cheated of our 
interest and attention" (WWR 2, 465). And he also praises the creativity of lyrical poetry precisely for being "a free impulse of genius, without any admixture of deliberation of reflection" (WWR 2, 466).

As it is possible to view empirical objects in a way that somehow transcends their merely sensuous characteristics, this involves ultimately overcoming not sensory perception as such - which seems to be Hegel's and perhaps also Plato's ideal - but the dominance of our personal appetites, urges, worries and needs, in order to value the purposefulness of the thing and appreciate it for the thing that it is. Schopenhauer's analysis of the senses and of perceptual cognition is integral to his approach of aesthetic perception. For in aesthetic perception, sensory perception is not discarded, for it is driven by what cannot be discarded in principle, namely will. One should not forget that, in Schopenhauer's view, the brain is a tool of the will: it assists the will in appearing in the phenomenal world. Yet in aesthetic cognition the cerebral system is no longer subservient to the individual will and operates, as it were, detached from it. This does not imply that we are merely passive mirrors, as Schopenhauer nevertheless oftentimes suggests, and that our mind is "temporarily cleared of the will, of all desire, emotion and felt need" ${ }^{\prime 7}$. On the contrary, perceiving an object aesthetically requires a heightened state of awareness in which the character and content of aesthetic consciousness is fully determined by the aesthetic correlate. The ordinary ways of locating myself temporally, spatially and causally abate, since sensory, imaginative perception of the aesthetic object suspends taking into account the ways in which the aesthetic correlate is causally or conceptually related to other things, that is to say, I transcend the kind of perception and cognition that is subservient to the principle of sufficient reason. This is hugely important. Instead of accepting what seems to have become

\footnotetext{
${ }^{7}$ Chris Janaway, 'Responses to Commentators', p. 133.
} 
a consensus opinion in Schopenhauer research, namely that Schopenhauer argues that aesthetic contemplation requires us to transcend sensory perception by 'spiritualising' it and becoming an unemotional and passive receptacle, I would like to emphasise that Schopenhauer does not defend such a view. On the contrary, he vindicates that aesthetic consciousness requires us to "devote the entire power of our mind to intuition ... letting the whole of consciousness be filled with peaceful contemplation" of the aesthetic object (WWR $1,210)$. Hence, relinquishing the ordinary way of considering things and "ceasing to follow under the guidance of the forms of the principle of sufficient reason" does not imply discarding perceptual and imaginative engagement with the world. Contrary to what most commentators suggest, Schopenhauer's characterisation of aesthetic perception (or intuition) does not involve "a condition of pure passivity" in which, as Julian Young unjustly argues, "the mind becomes a reflecting tabula rasa" ${ }^{8}$ On the contrary, active imaginative engagement with the aesthetic aspects of the world is a necessary requirement of aesthetic attention. Schopenhauer avers that "everyone who reads a poem or contemplates a work of art must of course contribute from his own resources", and every beholder must co-operate with the work of art. Furthermore, his aesthetic pleasure results at least partly from "the fact that every work of art can only work through the medium of the imagination. It must therefore excite the imagination, which can never be left out of the question and remain inactive." And Schopenhauer significantly adds: "This is a condition of aesthetic effect, and therefore a fundamental law of all the fine arts." (WWR 2, 463; italics added)

Thus, that aesthetic perception requires disinterestedness, idealisation and selftranscendence does not imply that we must become passive, estranged spectators of the

\footnotetext{
${ }^{8}$ Julian Young, Nietzsche's Philosophy of Art, p. 122.
} 
world in aesthetic contemplation. ${ }^{9}$ On the contrary, as we will see, on Schopenhauer's account, homo aestheticus is concerned with creating a place in which he feels at home, with expanding his emotional horizons, by inducing imaginative sympathy with what surrounds him.

\section{Aesthetic Perception as Disinterested Self-Transcendence}

According to Nietzsche, Schopenhauer's aesthetics centres exclusively on the spectator and neglects the perspective of the artist, and would therefore identify aesthetic appreciation with disembodied, dispassionate contemplation, which is ultimately 'hostile to life' ${ }^{10}$ Many commentators have followed Nietzsche's (unjust) condemnation of Schopenhauer's aesthetic theory. Although Schopenhauer is clearly more interested in the ecstasy of genius than in his deliberate artistic activity, Schopenhauer's analysis of aesthetic subjectivity is not primarily concerned with passive spectatorship, as Nietzsche and numerous commentators hold. Schopenhauer does not develop two radically distinct accounts of aesthetic perception: one focusing on the artist and the other on the spectator. Although aesthetic contemplation is a fundamental part of artistic creativity, it does not follow that Schopenhauer dismisses the perspective of the artist, as Nietzsche nevertheless suggests. On the contrary, Schopenhauer's account of genius offers a privileged way to discover the richness and subtlety of his aesthetic attitude theory. Ultimately, the art lover and the artist are not radically different, their aesthetic attitude differs only gradually, and represents two sides of the same phenomenon: aesthetic consciousness, which is a superior state of mind, surpassing ordinary self-oriented consciousness, by being engaging, uplifting, and absorbing. It basically requires transcending our personal, instrumental interests and valuations, and

\footnotetext{
${ }^{9}$ Here I take issue with Bernard Reginster, 'Knowledge and Selflessness'.

${ }^{10}$ See Friedrich Nietzsche, On the Genealogy of Morality.
} 
becoming actively engaged with a beautiful object for its own sake, i.e., a process of what one might call disinterested self-transcendence.

One of Schopenhauer's key thoughts is that perceiving something aesthetically requires suspending our merely personal interests in it and focusing exclusively on the way in which the object presents itself to us. Whilst we spend the larger part of our lives looking restlessly for objects that can satisfy our needs and desires, the beauty of a string quartet, a landscape, a flower or a painting urges us to admire the singular way in which things appear to us. On such occasions, we take a disinterested interest in things and "we stop considering the Where, When, Why, and Wherefore of things, but simply and exclusively consider the What", and "we do not allow our consciousness to become engrossed by abstract thinking, concepts of reason; but if, instead of all this, we devote the entire power of our mind to intuition and immerse ourselves in this entirely ... we forget individuality, our will ... and we can no longer separate the intuited from the intuition as the two have become one, and the whole of consciousness is completely filled and engrossed by a single intuitive image" (WWR 1, 210). What Schopenhauer implies here is that, when enjoying the beauty of a Beethoven string quartet, for instance, my attention is not focussed on some external interest, profit or use the music may have for me, but on the unique performance of the string quartet itself here and now. I am wholly devoted to the unique, irreplaceable performance of this very string quartet. No other piece of music would 'do just as well'. Disinterested aesthetic perception is thus not passive or indifferent, but presupposes engaging with a singular object and appreciating it in and because of its unique significance. Schopenhauer thus rightly characterises aesthetic engagement as an attitude which is not determined by selfinterest and is entirely devoted to the present object. He overstates his case here, since not every aesthetic engagement demands the kind of complete self-loss he evokes. None the 
less, Schopenhauer's insistence that pure aesthetic contemplation cannot be reduced to conceptually understanding an object or immediately satisfying personal desires is plausible. Even though aesthetic contemplation ultimately fulfils our need for security and harmony and may therefore ultimately never be wholly unconditional, there is still an important distinction between the way in which we consider objects in daily life with a view of fulfilling our personal needs, appetites and wants, and the way in which we engage aesthetically with things, that is, when we no longer consider them as mere means to an end but as ends in themselves, to be admired for their own sake (see WWR 2, Ch. 31).

However, admiring something aesthetically does not imply that we no longer perceive the particular, unique features of it. Although Schopenhauer may be right that, from a purely aesthetic point of view, "it is then all the same whether we see the setting sun from a prison or from a palace", enjoying this particular sunset in Venice will not guarantee that I will equally enjoy another Venetian sunset (WWR 1, 232). As Schopenhauer justly contends, my attentiveness is directed towards the way this particular object presents itself to me, and not towards any personal advantage, profit or therapeutic reward it may offer. My attention is wholly devoted to the way in which this irreplaceable object appears to me.

This immensely important requirement of aesthetic experience might further explain why Schopenhauer's so-called Platonic idealism should not be taken at face value. Insisting that aesthetic contemplation is concerned merely with the universal category or 'paradigm' of concrete particulars is plainly wrong. Let us take Dutch still life painting, which Schopenhauer admires immensely, as a case in point. Whatever else it is that such paintings offer, they are clearly not devoted solely to timeless universals. Their often extremely moving effect follows from their exquisite eye for seemingly futile, contingent details, fleeting events and transient, ethereal phenomena. They are not about flowers or food in 
general, nor about the timeless essence of carnations or tulips. By insisting that the proper object of aesthetic contemplation is a Platonic Idea, that is to say, a representation which has laid aside merely the subordinate forms of the phenomenon, all of which we include under the principle of sufficient reason, he unjustly downplays one of the most fundamental features of aesthetic contemplation, namely its focus upon the singularity of aesthetic objects.

However, as I have already indicated, what Schopenhauer refers to as (Platonic) Ideas in the context of art is not to be confused with concepts or universal categories, for Ideas "develop representations that are novel with respect to concepts sharing the same name" (WWR 1, 277). This is clearly reminiscent of Kant's definition of the aesthetic idea in the Critique of Judgment as "a presentation of the imagination which prompts much thought, but to which ... no determinate concept can be adequate" (§ 49, 5:314; translation modified). Yet, contra Kant, Schopenhauer sets up a contrast between ordinary cognition, which is imperfect for being subordinate to the will and the forms of the principle of sufficient reason, and aesthetic cognition which is pure and unclouded, that is to say, yields clear insight into the grades of objectification of the will, of the true thing-in-itself, thus into Platonic Forms or Ideas.

On Schopenhauer's account, perceiving an object aesthetically implies apprehending Platonic Ideas, which are definitely not concepts, "which can be communicated coldly and dispassionately by words", but "inexhaustible" perceptual objects, "which leave behind something that, in spite of all our reflection on it, we cannot bring down to the distinctness of a concept" (WWR 2, 465). The works of art that express such Ideas are the product of genius, i.e. not of a passive onlooker, but "a kind of superfluity, that of the power of knowledge beyond the measure for the service of the will", and can only be apprehended 
through imaginative perception, i.e. the ability to go beyond the bounds of merely conceptual cognition (WWR 2, 466).

The individual object will not therefore disappear from my consciousness, but it is in and through my intense attentiveness to it that a universal meaning may be discovered. Inspired by Plato and Kant, Schopenhauer rightly suggests that aesthetic values, and especially beauty, do not express merely personal preferences but invest objects with a peculiar significance. Beauty challenges us to capture and assess the exceptional meaning an object has. Beauty possesses existential value. We do not have to agree with Schopenhauer that we perceive Platonic Ideas in aesthetic contemplation to understand that aesthetic values are inextricably entwined with the peculiar meaning of things - things that challenge us to explore and deepen our lives in their light.

As I have already indicated, Schopenhauer exaggerates, when he advances that we lose ourselves completely in the object that we perceive (see WWR 1, 210-212; 218-219). It would be sufficient to point out that aesthetic contemplation requires us to suspend our consideration of the causal and conceptual connections the object has with other objects and our self-centred interests. The so-called complete 'self-loss', which Schopenhauer nevertheless heavily emphasises, cannot be a sufficient condition for having an aesthetic experience. Aesthetic experience does require that we temporarily cast aside our selfinterest and, as it were, surrender our attention to the present object for its own sake. Contra Schopenhauer, I would suggest that temporarily suspending our egocentric interests, needs and desires does not, however, preclude us from returning to our individual interests, experiences and emotions in aesthetic contemplation. The 'self-loss' of aesthetic contemplation is not orgiastic or mystical: a link with our personal concerns is suspended but does not disappear altogether. In aesthetic contemplation a link remains with that which is 
suspended. Our personal aspirations are merely temporarily set aside, but are not completely abolished. Aesthetic perception is still contemplative: we become, as it were, the impartial spectator of our personal desires, interests and emotions. Claiming that in aesthetic contemplation our perception is completely detached from our will and "that the consciousness of our own selves vanishes" (WWR 2, 418) is definitely an overstatement. Indeed, aesthetic consciousness requires an "abnormal excess of intellect", especially of its imaginative capacity, and being immersed in the object, but cannot be identified with Dionysian rapture by which the self becomes an insignificant plaything of overwhelming forces. Aesthetic contemplation remains what the term suggests, namely contemplative, which implies that a passive individual is transformed into an imaginatively engaged subject that becomes disassociated from its personal concerns, needs and urges (see WWR 1, 221). ${ }^{11}$ Now, Schopenhauer's attempt to undermine Plato's critique of the illusory nature of art, by pointing out that art does offer insight into eternal timeless universals, is - as said - hardly plausible as a general characterisation of the value of art and beauty. None the less, Schopenhauer's emphasis on the cognitive import of art, i.e. the knowledge and insights works of art may yield, is hugely important. The insights works of art yield are usually tied up with specific experiences that cannot be reduced to discursive knowledge. And even though some artworks express experiences that can be formulated as propositions, artworks still connect with, for instance, the peculiar, non-propositional way in which someone experiences certain emotions or ideas. The existential fear that paintings by Edvard Munch or Francis Bacon depict has been conveyed by philosophers such as Kierkegaard and Heidegger, but Munch and Bacon show us none the less in a unique, non-propositional way

\footnotetext{
${ }^{11}$ Schopenhauer uses the terms 'Beschaulichkeit' and 'Kontemplation' to characterise aesthetic perception. Payne as well as Norman, Welchman and Janaway translate 'Beschaulichkeit' as 'thoughtfulness'. 'Meditativeness' might have been a better option, since cognition of the Ideas does not follow the principle of sufficient reason and is non-conceptual.
} 
what it is like to be overwhelmed by such an emotion. Schopenhauer thus rightly insists that art can have cognitive value. Yet the disturbing knowledge we acquire through, for instance, the psychotic main character in Alfred Hitchcock's Psycho (1960) does not (merely) reveal eternal Ideas but crucial aspects of certain pathologies, on the basis of which we gain insight into the darker aspects of the human mind and the suffocating atmosphere that characterises some parent-child relationships. Instead of offering immediate access to timeless essences, many works of art yield experiential knowledge of historically situated events, characters, views and emotions. This does not preclude valuing works of art because of the universal truths about man and world which they convey. An aesthetic experience is, however, not merely cognitive (and Schopenhauer fortunately never claims this).

According to Schopenhauer, aesthetic experience is characterised by the contemplating subject's awareness of an allegedly pleasurable state of will-lessness. Schopenhauer describes our will-lessness as a state of bliss, in which we seem to become an eye of the world (Weltauge) that loses itself completely in the object under contemplation. We cease to be aware of ourselves as distinct from the object. The aesthetic pleasure that I thus experience originates from two sources. First of all, I realise that my will no longer dominates me: I feel liberated from the burden of willing - this is the 'negative' aspect of aesthetic pleasure. Furthermore, I take pleasure in becoming immersed into the core of the perceived object - this is a form of 'positive' pleasure, which is not reducible to the feeling of liberation from the pain or suffering the will causes. This latter form of pleasure indeed originates from the objective intuition of the timeless Idea that the object instantiates:

Cognition of the beautiful always posits the pure cognizing subject at the same time as, and inseparably from, the cognition of the Idea as object. And yet the source of 
aesthetic pleasure will sometimes be located more in the apprehension of the Ideas ..., and sometimes more in the happiness and peace of mind of pure cognition that has been liberated from all willing and thus from all individuality free from all willing, and thus from all individuality and the pain that come from it. (WWR 1, 250)

Several commentators discover remnants from Kant's aesthetics in "the happiness and peace of mind ... liberated from all willing", for this clearly reminds of the disinterested nature of Kantian aesthetic judgement. Nietzsche and Heidegger, amongst others, have linked Schopenhauer's aesthetics of will-lessness with Kant's emphasis upon the disinterested nature of aesthetic pleasure and judgment, and have judged Schopenhauer's analysis inferior to its predecessor's. The relation between Kant's and Schopenhauer's aesthetics is, however much more complicated than has often been assumed and Schopenhauer's theory certainly moves beyond Kant's in many significant ways. ${ }^{12}$

\section{Artistic Creativity and Imaginative Engagement}

Schopenhauer's characterisation of aesthetic pleasure does not apply merely to the aesthetic spectator but (pace Nietzsche) also to the artist, which Schopenhauer refers to as 'genius'. The genius is not someone who has merely personal relations, but "a pure intellect that as such belongs to the whole of mankind", and that "has become unfaithful to its destiny", which is the service of his will (WWR 2, 445; 440). For, unlike ordinary people, artists are able to maintain a state of pure will-less contemplation for a long time and to leave entirely out of sight their own interests, willing, and aims, and hence "to remain as the pure cognitive subject, the clear eye of the world: and this not just momentarily, but for as

\footnotetext{
${ }^{12}$ See The Sublime in Schopenhauer's Philosophy, especially Chs. 3 and 4.
} 
long and with as much clarity of mind [Besonnenheit] as is necessary to repeat what has been grasped in the form of well-considered art" (WWR 1, 219). Artists have an unnatural capacity for heightened perception: they see with more detail, intensity and accuracy, which allows them to create imaginative artworks that offer cognition beyond the principle of sufficient reason. The genius has the capacity to distract from the immediate connections between things and 'express clearly what nature only stutters' (WWR 1, 262).

As Matthias Kossler has emphasised, the genius's power to tear away cognition from the service of the will - his 'clarity of mind' or 'thoughtful awareness' (Besonnenheit) - has a paradoxical role to fulfil in both the apprehension of the timeless essence of things and the execution of the artwork (see WWR 2, 437-443). ${ }^{13}$ For it is hard to understand how the artist's Besonnenheit might offer both an escape from (individual) willing, which allows for pure aesthetic contemplation, and the purposeful, hence will-driven activity of conveying the perception of timeless Ideas through a work of art.

But Schopenhauer does not reduce the artistic creativity and genius merely to thoughtful awareness, and it would have been odd if had done so. He also rightly stresses the artist's vehemence and passionateness of willing and, perhaps even more importantly, his imaginative capacities (Phantasie) to account for the activity of expressing - instead of merely conveying - the perceived Ideas in a work of art. Schopenhauer is surely right to refrain from reducing artworks to mere replicas of universal essences, and to put great emphasis on the expressive function of imagination, which allows artists to see in things not "what nature actually created, but rather what it was trying unsuccessfully to create" and "to complete, arrange, amplify, fix, retain, and repeat at pleasure all the significant pictures

\footnotetext{
${ }^{13}$ See Matthias Kossler, 'The Artist as Subject of Pure Cognition', p. 201-202.
} 
of life ... On this rests the high value of imagination as an indispensable instrument of genius" (WWR 1, 220; WWR 2, 431).

The paradoxical foundations of Schopenhauer's view of aesthetic contemplation none the less remain intact: whilst the imaginative execution of a work of art, which strives to embody Ideas in particular representations, cannot take place without the activity of will, and is hence subordinate to the forms of the principle of sufficient reason, genius still consists in a decided predominance of pure knowing over willing, that is, the capacity to suspend knowledge according to the principle of sufficient reason, in order to grasp the inner essences of things. And this ability, in its turn, presupposes a purely objective frame of mind, so that it is as though the object alone existed without anyone to perceive it, and the entire consciousness is filled and absorbed by the perceived aesthetic correlate (see WWR $1, \S 34$ ). This is hugely significant. The basic characteristics of aesthetic engagement, namely selftranscendence and imaginative perception are not to be located exclusively in artists but also hold for art lovers and all people that spend time admiring the world aesthetically. Contrary to what most commentators suggest ${ }^{14}$, Schopenhauer's view of aesthetic perception cannot be reduced to passively mirroring the aesthetic qualities of a work of art: aesthetic contemplation requires an energetically active consciousness and "lively", enthusiastic engagement. Thus Schopenhauer insists that "everyone ... must of course contribute from his own resources" (WWR 1, 221; WWR 2, 462). Not merely the artist but the aesthetic beholder too actively engages with the work of art, for "every work of art can act only through the medium of the imagination. It must therefore excite the imagination, which can never be left out of the question and remain inactive. This is a condition of

\footnotetext{
${ }^{14}$ See, for instance, Daniel Came, 'Disinterestedness and Objectivity', p. 94; Christopher Janaway, 'Knowledge and Tranquillity', p. 58 and passim; Aaron Ridley, Nietzsche on Art, p. 121; Reginster, 'Knowledge and Selflessness', passim; Young, Nietzsche's Philosophy of Art, p. 122.
} 
aesthetic effect, and therefore a fundamental law of all the fine arts ... It must be born in the beholder's imagination." (WWR 2, 463; italics added)

Hence, both the artist and the lover of natural beauty and art are ultimately actively engaged, enthusiastic spectators that are capable of momentarily transcending their limited individual point of view and obtaining fundamental insights and passionate attunement to the true essences of things. They transcend their egocentric concerns and remain "lively and steadfast" and "linger for very long with mere intuition" (WWR 1, 221). ${ }^{15}$ Aesthetic consciousness is affectively heightened and cognitively enriched. Succinctly put, transcending cognition according to the principle of sufficient reason implies that awareness of the object is intensified and vividly transfigured by the power of imagination, so that consciousness of our practical, egocentric goals and concerns disappears.

\section{Conclusion}

Contrary to the standard view of Schopenhauer's aesthetic theory, I have argued that transcending subservience to the principle of sufficient reason does not turn aesthetic consciousness into a passive, disengaged receptacle of aesthetic properties and eternal forms. Schopenhauer's emphasis on what Nietzsche calls the Selbststeigerung typical of aesthetic delight does not imply a dispassionate, distant, intellectual, let alone a purely spiritual attitude towards the world. Schopenhauer's obsessive usage of terms such as 'objective', 'mirror', and especially 'will-less' to describe the phenomenological

\footnotetext{
${ }^{15}$ In a very illuminating passage Schopenhauer makes an important distinction between aesthetic contemplation and day-dreaming. A day-dreamer (Phantast) is chiefly concerned with manipulating reality to fit his own wishes and desires. He deceives himself "so that all he really comes to know are the relations between the figments of his imagination", and "will easily blend the images of his solitary self-amusement together with reality, for which he will then be unfit" (WWR 1, 220). Day-dreaming is self-deceptive, since it denies the 'transcendence' of external reality. A strong imagination is thus not a sufficient condition for aesthetic contemplation and creativity. Aesthetic consciousness also requires 'objective perception', which is not self-indulging, manipulative or merely looking for entertainment or excitement, but requires disinterested engagement with the world (ibid.).
} 
characteristics of aesthetic consciousness, and Nietzsche's spiteful criticism of the purportedly life-denying views of his 'noblest enemy' may well have obfuscated not only the accuracy and subtlety of Schopenhauer's analysis of aesthetic perception, but also the perhaps unsuspected affirmative potential of Schopenhauer's aesthetic theory and its just vindication of the imaginative engagement, exaltation and delightful self-transcendence which fundamentally characterise our most valuable (aesthetic) experiences.

\section{References}

Goehr, L. 'Schopenhauer and the Musicians: An Inquiry into the Sounds of Silence and the Limits of Philosophizing about Music', in D. Jacquette, Schopenhauer, Philosophy, and the Arts, Cambridge: Cambridge University Press, 1996, 200-228.

Janaway, C. 'Knowledge and Tranquillity: Schopenhauer on the Value of Art', in D. Jacquette, Schopenhauer, Philosophy, and the Arts, Cambridge: Cambridge University Press, 1996, 39-61.

Janaway, C. 'Responses to Commentators', The European Journal of Philosophy 17, 2009: $132-151$.

Kant, I. Critique of the Power of Judgment, Edited by Paul Guyer, Translated by Paul Guyer and Eric Matthews, Cambridge: Cambridge University Press, 2001.

Kossler, M. 'The Artist as Subject of Pure Cognition', in B. Vandenabeele, A Companion to Schopenhauer, Oxford: Wiley-Blackwell, 2012, 193-205.

Nietzsche, F. On the Genealogy of Morality, Translated by M. Clark and A. Swensen, Indianapolis, Hackett, 1998. 
Reginster, B. 'Knowledge and Selflessness: Schopenhauer and the Paradox of Reflection', in A. Neill and C. Janaway, Better Consciousness: Schopenhauer's Philosophy of Value, Oxford: Wiley-Blackwell, 2009, 99-119.

Vandenabeele, B. 'Schopenhauer and the Objectivity of Art', in B. Vandenabeele, A Companion to Schopenhauer, Oxford: Wiley-Blackwell, 2012, 219-233.

Vandenabeele, B. The Sublime in Schopenhauer's Philosophy, Basingstoke / New York: Palgrave Macmillan, 2015.

Young, J. Nietzsche's Philosophy of Art, Cambridge, Cambridge University Press, 1992. 